\title{
Antineutrophil Cytoplasmic Antibody-Associated Vasculitides: Could Geographic Patterns Be Explained by Ambient Ultraviolet Radiation?
}

\author{
PAUL A. GATENBY, ${ }^{1}$ ROBYN M. LUCAS, ${ }^{1}$ OLA ENGELSEN, ${ }^{2}$ ANNE-LOUISE PONSONBY, ${ }^{3}$ AND \\ MARK CLEMENTS ${ }^{1}$
}

Objective. This ecological study describes and quantifies the association between ambient ultraviolet (UV) radiation levels, including daily winter vitamin D effective UV radiation levels and the incidence of the 3 antineutrophil cytoplasmic antibody-associated vasculitides (AAVs): Wegener's granulomatosis (WG), microscopic polyangiitis (MPA), and Churg-Strauss syndrome (CSS). Latitudinal variation in occurrence of the AAVs, especially WG, has been previously reported. For other autoimmune diseases such as multiple sclerosis and type 1 diabetes mellitus, inverse associations with latitude are hypothesized to indicate a causative role for low UV radiation exposure, possibly acting via vitamin D status.

Methods. Published epidemiologic studies provided data on incident cases, total population of study regions, age-specific incidence rates, and study location. From these data and online age-specific population data, we calculated crude incidence rates, the expected number of cases (to control for possible age confounding), and measures of ambient UV radiation. Negative binomial regression models were used to calculate the incidence rate ratio (IRR) for a $1,000 \mathrm{joules} / \mathrm{m}^{2}$ increase in ambient UV radiation.

Results. The incidence of WG and CSS increased with increasing latitude and decreasing ambient UV radiation, with a stronger and more consistent effect across different UV radiation measures for WG, e.g., for average daily ambient clear sky erythemal UV radiation (WG: IRR 0.64 [95\% confidence interval (95\% CI) 0.44-0.94], $P=0.02$; CSS: IRR 0.67 [95\% CI 0.43-1.05], $P=0.08$; MPA: IRR 1.16 [95\% CI 0.92-1.47], $P=0.22$ ). There was no apparent latitudinal variation in MPA incidence.

Conclusion. Our findings are consistent with a protective immunomodulatory effect of ambient UV radiation on the onset of WG and CSS. We discuss possible mechanisms, including the effect of vitamin D on the immune system.

\section{INTRODUCTION}

The antineutrophil cytoplasmic antibody (ANCA)-associated vasculitides (AAVs) are an important group of inflammatory vascular diseases of small blood vessels, with both

Dr. Lucas's work was supported by a Multiple Sclerosis Research Australia Fellowship and the Royal Australasian College of Physicians Cottrell Fellowship. Dr. Engelsen's work was supported by the European Commission via the European Commission-Integrated Project INTARESE (018385-2).

${ }^{1}$ Paul A. Gatenby, MBBS, PhD, Robyn M. Lucas, MBChB, PhD, Mark Clements, PhD: Australian National University, Canberra, ACT, Australia; ${ }^{2}$ Ola Engelsen, PhD: Norwegian Institute for Air Research, Tromso, Norway; ${ }^{3}$ Anne-Louise Ponsonby, MBBS, PhD: Murdoch Childrens Research Institute, Melbourne, Victoria, Australia.

Address correspondence to Paul A. Gatenby, MBBS, PhD, The Canberra Hospital, PO Box 11, Woden, ACT 2606, Australia. E-mail: paul.gatenby@anu.edu.au.

Submitted for publication January 27, 2009; accepted in revised form May 27, 2009. overlapping and distinct features united by the association with ANCAs (1). Included are Wegener's granulomatosis (WG), microscopic polyangiitis (MPA), and Churg-Strauss syndrome (CSS) (2). The etiology of the AAVs is largely unknown, although they are widely believed to be autoimmune in origin, triggered by environmental events on an as-yet poorly characterized background of genetic susceptibility $(3,4)$. No single dominant environmental factor has emerged with the exception of particular medications in a minority of cases $(5,6)$. Epidemiologic studies have indicated clues, including silica exposure, infection, seasonal variation in occurrence, and the subject of this study, a latitudinal gradient. The latter is best documented for WG, which in both the Northern and Southern hemispheres appears to be more common at a higher latitude $(7,8)$, although the magnitude of the latitudinal gradient has not been formally quantified. Some studies suggest an inverse relationship between latitude and MPA (9), although there are exceptions to this (7).

Latitudinal gradients are seen in the autoimmune dis- 
eases multiple sclerosis and type 1 diabetes mellitus, and the chronic inflammatory Crohn's disease (10-12). All 3 are diseases in which Th1 cells play a predominant role $(13,14)$. This type of T cell also appears very important in the pathogenesis of WG (15-18). More recently, it has become clear that another subset of $\mathrm{T}$ cells, Th17 cells, may contribute to the pathogenesis of diseases that were until now considered to be predominantly mediated by Th1 cells (19). This includes multiple sclerosis and granulomatous diseases such as Crohn's disease and WG (20).

The most plausible hypothesis that has been raised to explain the latitude effect in immune diseases such as multiple sclerosis has been related to the interaction between vitamin $\mathrm{D}$ and the immune system. The active form of vitamin $\mathrm{D}, 1 \alpha, 25$-dihydroxyvitamin $\mathrm{D}_{3}$, has particular immunomodulatory effects involving inhibition of certain $\mathrm{T}$ lymphocytes (21), with the reduction in a number of important cytokines derived from both mononuclear phagocytes and $\mathrm{T}$ cells; of particular relevance to this study, one of its effects is to suppress Th1 cells, and more recently, Th17 cell responses $(20,22,23)$.

Sun exposure of the skin is the principal source of vitamin D for humans (24), and unless it is supplemented by diet, humans tend to be vitamin $\mathrm{D}$ deficient in higher latitude locations (25). It is important to recognize, however, that ultraviolet (UV) radiation exposure may have effects on the immune system independent of vitamin $D$, and any mechanisms remain speculative at this stage (26).

The objective of this ecological study was to describe and quantify the association between regional ambient UV radiation levels, including vitamin $\mathrm{D}$ effective UV radiation levels, and the incidence of the 3 AAVs: WG, MPA, and CSS. Contrary to previous studies that searched only for latitude dependencies $(9,27)$, we compared worldwide incidence data with estimates of ambient UV radiation levels in addition to latitude, providing more pertinent descriptors of UV radiation exposure.

\section{MATERIALS AND METHODS}

Published epidemiologic studies of AAVs and each of the 3 diseases separately were sourced from PubMed using the following search strategy. We assessed studies that included the key words of the specific disease, e.g., "Wegener's granulomatosis" and "incidence," that were published before December 2008. Initial articles were used to check the completeness of the search by comparing the references with the articles obtained. Further unpublished work was obtained from the published abstracts of the 13th Vasculitis and Antineutrophil Cytoplasmic Antibody conference held in Cancun, Mexico in 2007.

We included studies that 1) used the diagnostic criteria developed by the American College of Rheumatology (ACR) (28) or the Chapel Hill Consensus Conference (CHCC) (29), 2) indicated a well-defined source population from which the incident cases arose and underlying population data were provided (at least total or adult-only population), 3) used complementary methods to ensure thorough detection of cases, and 4) did not restrict cases to only those with a particular phenotype subgroup of dis- ease (e.g., only cases with renal disease). We restricted our analysis to published series where the population denominator was clear. Therefore, we did not use the study from Kuwait (30), a hospital-based study from Sweden (31), or the report from The Glomerular Disease Collaborative Network (32). We also excluded an important study from New Zealand that used discharge codes in a national data set that was not strictly comparable with the other studies (8). Three other studies did give rise to some concerns: the study from Lithuania (33) was hospital based and may have missed community cases, the diagnostic criteria used by Zeft et al (34) were not stated in their abstract, and the study from Japan (35) was based on referral to a renal unit and may have missed those with nonrenal disease. However, the denominator population in this case was clearly defined (35), and other sources (36) attest to the rarity of WG in this region. We extracted the number of cases of each disease entity, noting the location, year of publication, and the source population, e.g., general, adult-only.

We used online census data (see Supplemental Appen$\operatorname{dix} \mathrm{A}$, available in the online version of this article at http:// www3.interscience.wiley.com/journal/77005015/home) for each study region (using the population estimate closest to the time period of the study, and if regional data were not available, applying the age distribution of the smallest available unit to the population figures in the published article) to derive the total population of the study region (by 5-year age groups), ensuring that this was consistent with the population data cited in the published study.

Where studies were reported in separate articles over several time periods, we used the total time period in the person-time denominator to provide the most stable incidence estimate. We then recalculated the crude incidence and 95\% confidence intervals (95\% CIs) at each location using a consistent method (Poisson distribution). For one study (34) that did not provide a total source population, we back calculated from the total number of cases $(n=36)$ with AAV and the reported annual incidence rate of 11.4 per million for 12 years to derive a population estimate.

We extracted the available age-specific incidence rates for each disease (37-39). We then calculated the mean incidence rate for each age group and multiplied this by the population of the relevant age group for each study region. This provided the number of cases of each disease that would be expected in each age group and in each region if all of the regions had the same age-specific incidence rates. By summing the number of cases across the age groups, we calculated the expected total number of cases in the region, removing any confounding effect of any differences in the age structures of the populations (indirect age standardization). Because only a few studies noted the observed sex distribution of cases with each form of vasculitis, it was not possible to standardize for both age and sex.

Using the latitude and longitude of the largest city in each study and the time period during which the study was performed, we used satellite data to derive the mean daily ambient UV radiation level and the mean daily winter UV radiation level for each study (see Supplemental Appendix A, available in the online version of this article at http://www3.interscience.wiley.com/journal/77005015/ 
home). We estimated both the ambient UV radiation level weighted to erythemally effective wavelengths ( $\left.U_{\text {ery }}\right)$ (40) and to vitamin D effective wavelengths ( $\left.\mathrm{UV}_{\text {vitD }}\right)(41)$ under both clear sky and cloud-inclusive conditions. We used winter UV radiation levels in addition to mean daily ambient UV radiation levels (across the time period of the study) because there is a stronger latitudinal gradient in winter UV radiation compared with summer UV radiation (42). Additionally, it is the lower vitamin D effective UV radiation during the winter that limits vitamin D production from skin irradiation at high latitudes (25).

Statistical analysis. We first examined the correlation between the crude incidence rates and each measure of ambient UV radiation level using Pearson's correlation coefficients ( $P$ value test if the correlation was different from zero or if there was no correlation). We then used a negative binomial regression model (to account for the differences in precision between studies and the different age distributions of the source populations) (43) with the observed number of cases as the dependent variable, a measure of ambient UV radiation level as the independent variable, and the log of the expected number of cases as an offset to calculate the incidence rate ratio (IRR) for a 1,000 joules $/ \mathrm{m}^{2}$ increase in each measure of ambient UV radiation. The various measures of ambient UV radiation were highly correlated and provided similar results, so that only results for the average daily ambient erythemal clear sky $\mathrm{UV}$ radiation ( $\mathrm{UV}_{\text {ery }}$ [clear]) doses and average daily winter ambient vitamin D effective cloud-inclusive UV radiation (winter $\mathrm{UV}_{\text {vitD }}$ [cloud]) doses are reported here.

We used Cook's distance (44) to test for highly influential data points and performed a sensitivity analysis to confirm that the findings were somewhat robust to our criteria for inclusion. Cook's distance is a measure of the change in model predictions when deleting the ith observation. Here we excluded possibly influential points one by one, and repeated the analyses. Influence was also measured using the dfbeta statistics (45), which are a standardized measure of the change in the parameter estimate when deleting the ith observation.

In a second sensitivity analysis, we assessed the influence of nonuniformity of different study-specific population denominators, i.e., the total population of the region or populations ages 15-20 years and older. We extracted the proportion of cases that were in the pediatric age groups from those studies where pediatric patients were included in the source population. We used these data to recalculate the probable total number of cases (adult and pediatric) from those articles drawing only from adult clinical services. This resulted in only very small adjustments to the total number of cases and therefore to the incidence rate. All analyses were performed in Stata, version 9.2 (StataCorp, College Station, TX).

\section{RESULTS}

There were 13 eligible studies for WG, 10 studies for CSS, and 10 studies for MPA (Table 1), covering a latitude range of $35.30^{\circ}$ South to nearly $70^{\circ}$ North.
Crude incidence rates varied widely for all of the diseases, e.g., WG incidence was 0 per million in Japan and 8.98 per million in Norwich, UK. There was a strong correlation between the absolute latitude and all of the measures of ambient UV radiation level, ranging from $\mathrm{r}=$ $-0.87(P<0.001)$ for winter $\mathrm{UV}_{\mathrm{vitD}}$ (cloud) to $\mathrm{r}=-0.99(P$ $<0.001$ ) for $U_{\text {ery }}$ (clear).

Latitude. Although there was no apparent correlation between the crude incidence of MPA and latitude ( $\mathrm{r}=$ $0.01, P=0.98$ ), the crude incidence rates of both CSS and WG increased with increasing latitude $(\mathrm{r}=0.43, P=0.22$ and $\mathrm{r}=0.62, P=0.02$, respectively). In the negative binomial regression, there was a modest increase in the incidence of CSS and WG per higher degree of latitude of $3.4 \%$ (IRR 1.04, 95\% CI 0.99-1.08; $P=0.11$ ) and $3.5 \%$ (IRR 1.04, 95\% CI 1.00-1.07; $P=0.03$ ), respectively. MPA incidence again did not appear to be associated with latitude (IRR 0.99, 95\% CI 0.97-1.01; $P=0.23$ ).

Ambient UV radiation. There was a strong inverse correlation between ambient UV radiation level and WG incidence ( $\mathrm{UV}_{\text {ery }}$ [clear]: $\mathrm{r}=-0.62, P=0.02$; winter $\mathrm{UV}_{\text {vitD }}$ [cloud]: $\mathrm{r}=-0.60, P=0.03$ ), and a more modest inverse correlation with CSS incidence $\left(\mathrm{UV}_{\text {ery }}[\mathrm{clear}]: \mathrm{r}=\right.$ $-0.43, P=0.21 ; \mathrm{UV}_{\text {vitD }}[$ cloud]: $\mathrm{r}=-0.48, P=0.16)$. In contrast, MPA incidence was not correlated with any measure of ambient UV radiation level (UV ${ }_{\text {ery }}$ [clear]: $\mathrm{r}=$ -0.02, $P=0.95 ; \mathrm{UV}_{\text {vitD }}$ [cloud]: $\left.\mathrm{r}=-0.13, P=0.73\right)$.

In the negative binomial regression model, the incidence of both WG and CSS was inversely associated with all of the measures of ambient UV radiation level (Figure 1). For an increase in $U_{\text {ery }}$ (clear) of 1,000 joules $/ \mathrm{m}^{2}$ (e.g., the difference between Vilnius, Lithuania [1,733.11 joules $\left./ \mathrm{m}^{2}\right]$ and Lugo, Spain $\left[2,665.61\right.$ joules $\left.\left./ \mathrm{m}^{2}\right]\right)$, the CSS incidence decreased by $33 \%$ (IRR $0.67,95 \%$ CI $0.43-1.05 ; P=0.08$ ), and decreased by $23 \%$ (IRR $0.77,95 \%$ CI $0.62-0.95$; $P=0.02$ ) for a 1,000 joules $/ \mathrm{m}^{2}$ increase in winter $\mathrm{UV}_{\text {vitD }}$ (cloud). WG incidence decreased by $36 \%$ (IRR 0.64 , 95\% CI $0.44-0.94 ; P=0.02$ ) for a 1,000 joules $/ \mathrm{m}^{2}$ increase in $\mathrm{UV}_{\text {ery }}$ (clear), and decreased by $25 \%$ (IRR $0.75,95 \%$ CI $0.62-0.89 ; P=0.001$ ) for a 1,000 joules $/ \mathrm{m}^{2}$ increase in winter $\mathrm{UV}_{\text {vitD }}$ (cloud). For both CSS and WG, the strongest inverse associations were with measures of winter ambient UV radiation levels. There was no statistically significant variation in MPA incidence (Figure 1) for any measure of ambient UV radiation level when all of the data points were included (UV ${ }_{\text {ery }}$ [clear]: IRR 1.16, 95\% CI 0.92-1.47; $P$ $=0.22$ and winter $\mathrm{UV}_{\text {vitD }}$ [cloud]: IRR 1.05 , 95\% CI $0.94-$ 1.18; $P=0.37)$.

Sensitivity analyses. For all 3 diseases, the Lima, Peru data were influential (CSS: Cook's distance $=0.87$, MPA: Cook's distance $=0.79$, WG: Cook's distance $=0.60$ ). In addition, there was some evidence that the Miyazaki, Japan and Canberra, Australia data were influential for WG, using measures for change in model fit and change in estimated parameters.

When excluding the Lima, Peru data, although point estimates continued to show decreasing CSS and WG in- 
Table 1. Studies reporting the population-based incidence of antineutrophil cytoplasmic antibody-associated vasculitides used in this analysis*

\begin{tabular}{|c|c|c|c|c|c|}
\hline \multirow[b]{2}{*}{ Author, year (ref.) } & \multirow{2}{*}{$\begin{array}{l}\text { Time period } \\
\text { of study }\end{array}$} & \multirow{2}{*}{$\begin{array}{c}\text { Location } \\
\text { (latitude, longitude) }\end{array}$} & \multicolumn{3}{|c|}{ Crude incidence per million population (95\% CI) } \\
\hline & & & CSS & MPA & WG \\
\hline $\begin{array}{l}\text { Sanchez-Torres et al, } \\
2006 \text { (61) }\end{array}$ & 1990-2004 & $\begin{array}{l}\text { Lima, Peru } \\
\quad\left(12.00^{\circ} \mathrm{S}, 76.58^{\circ} \mathrm{W}\right)\end{array}$ & $0.11(0.01-0.40)$ & $3.13(2.36-4.06)$ & $0.39(0.16-0.81)$ \\
\hline Fujimoto et al, 2006 (35) & $2000-2004$ & $\begin{array}{l}\text { Miyazaki, Japan } \\
\quad\left(31.90^{\circ} \mathrm{N}, 131.43^{\circ} \mathrm{E}\right)\end{array}$ & 0.00 & & 0.00 \\
\hline $\begin{array}{l}\text { Ormerod and Cook, } 2008 \\
\text { (64) }\end{array}$ & 1995-2004 & $\begin{array}{l}\text { Canberra, Australia } \\
\quad\left(35.30^{\circ} \mathrm{S}, 149.15^{\circ} \mathrm{E}\right)\end{array}$ & $1.81(0.78-3.57)$ & $3.63(2.07-5.89)$ & $8.61(6.09-11.80)$ \\
\hline $\begin{array}{l}\text { Gonzalez-Gay et al, } 2003 \\
\text { (39) }\end{array}$ & 1988-2001 & $\begin{array}{l}\text { Lugo, Spain } \\
\quad\left(43.00^{\circ} \mathrm{N}, 7.50^{\circ} \mathrm{W}\right)\end{array}$ & $1.20(0.33-3.07)$ & $10.18(7.05-14.2)$ & $3.59(1.86-6.28)$ \\
\hline Zeft et al, 2005 (34) & 1993-2004 & $\begin{array}{l}\text { Montana, US } \\
\left(46.87^{\circ} \mathrm{N}, 114.00^{\circ} \mathrm{W}\right)\end{array}$ & & $2.85(1.30-5.41)$ & $8.55(5.63-12.40)$ \\
\hline $\begin{array}{l}\text { Reinhold-Keller et al, } \\
2002(27)\end{array}$ & 1998-1999 & $\begin{array}{l}\text { South Germany } \\
\left(48.00^{\circ} \mathrm{N}, 7.85^{\circ} \mathrm{E}\right)\end{array}$ & $0.95(0.26-2.42)$ & $1.66(0.67-3.41)$ & $5.44(3.45-8.16)$ \\
\hline $\begin{array}{l}\text { Reinhold-Keller et al, } \\
2005 \text { (65) }\end{array}$ & $1998-2002$ & $\begin{array}{l}\text { North Germany } \\
\quad\left(53.87^{\circ} \mathrm{N}, 10.70^{\circ} \mathrm{E}\right)\end{array}$ & $1.01(0.55-1.69)$ & $2.66(1.88-3.67)$ & $8.57(7.10-10.30)$ \\
\hline Watts et al, 2001 (66) & 1988-1998 & $\begin{array}{l}\text { Norwich, UK } \\
\quad\left(52.63^{\circ} \mathrm{N}, 1.30^{\circ} \mathrm{E}\right)\end{array}$ & $2.62(1.43-4.39)$ & $7.11(5.03-9.76)$ & $8.98(6.62-11.90)$ \\
\hline $\begin{array}{l}\text { Dadoniene et al, } 2005 \\
\text { (33) }\end{array}$ & 1990-1999 & $\begin{array}{l}\text { Vilnius, Lithuania } \\
\left(54.67^{\circ} \mathrm{N}, 25.27^{\circ} \mathrm{E}\right)\end{array}$ & $1.11(0.41-2.41)$ & $2.58(1.41-4.33)$ & $1.84(0.88-3.39)$ \\
\hline Knight et al, 2006 (59) & 1975-2001 & Sweden $\left(60^{\circ} \mathrm{N}, 15^{\circ} \mathrm{E}\right)$ & & & $7.09(6.75-7.44)$ \\
\hline Haugeberg et al, 1998 (60) & 1992-1996 & $\begin{array}{l}\text { Kristiansand, Norway } \\
\left(63.12^{\circ} \mathrm{N}, 7.75^{\circ} \mathrm{E}\right)\end{array}$ & $2.66(0.32-9.61)$ & $6.65(2.16-15.5)$ & $6.65(2.16-15.5)$ \\
\hline $\begin{array}{l}\text { Koldingsnes and Nossent, } \\
2000 \text { (38) }\end{array}$ & 1984-1998 & $\begin{array}{l}\text { Northern Norway } \\
\quad\left(69.67^{\circ} \mathrm{N}, 19.00^{\circ} \mathrm{E}\right)\end{array}$ & & & $7.96(5.99-10.40)$ \\
\hline Watts et al, 2001 (67) & 1988-1998 & $\begin{array}{l}\text { Tromsø, Norway } \\
\quad\left(69.67^{\circ} \mathrm{N}, 18.90^{\circ} \mathrm{E}\right)\end{array}$ & $0.39(0.05-1.41)$ & $2.15(1.07-3.85)$ & $8.41(6.09-11.3)$ \\
\hline
\end{tabular}

cidence with increasing ambient UV radiation levels, these associations were no longer significant (CSS: UV $\mathrm{ery}_{\text {eclear] }}$ IRR 0.87 [95\% CI $0.44-1.74, P=0.69$ ] and winter $\mathrm{UV}_{\text {vitD }}$ [cloud] IRR 0.67 [95\% CI $0.31-1.43, P=0.30]$; WG: UV ery [clear] IRR 0.78 [95\% CI $0.47-1.29, P=0.33$ ] and winter $\mathrm{UV}_{\text {vitD }}$ [cloud] IRR 0.64 [95\% CI 0.33-1.25, $P=0.19$ ]). There was little change to the estimates of IRR for MPA, but notably, the point estimates were consistently $>1$, i.e., increasing incidence with increasing ambient UV radiation levels (UV ${ }_{\text {ery }}$ [clear]: IRR 1.28, 95\% CI 0.78-2.10; $P=0.33$ and winter $\mathrm{UV}_{\text {vitD }}$ [cloud]: IRR 1.29, 95\% CI 0.62-2.69; $P=0.49$ ).
In excluding the Miyazaki, Japan data (WG only), there was no appreciable change in the IRR estimates of decreasing WG incidence with measures of increasing ambient UV radiation levels per 1,000 joules $/ \mathrm{m}^{2}$ increase $\left(\mathrm{UV}_{\text {ery }}\right.$ [clear]: IRR 0.71, 95\% CI 0.53-0.95; $P=0.02$ and winter $\mathrm{UV}_{\text {vitD }}$ [cloud]: IRR 0.77, 95\% CI 0.68-0.87; $P<0.001$ ).

When excluding the Canberra, Australia data (WG only), there was an increase in the estimates of IRR (i.e., a stronger association between WG incidence and ambient UV radiation), and these estimates were no longer influenced by exclusion of the Lima, Peru data (WG incidence: $U_{\text {ery }}$
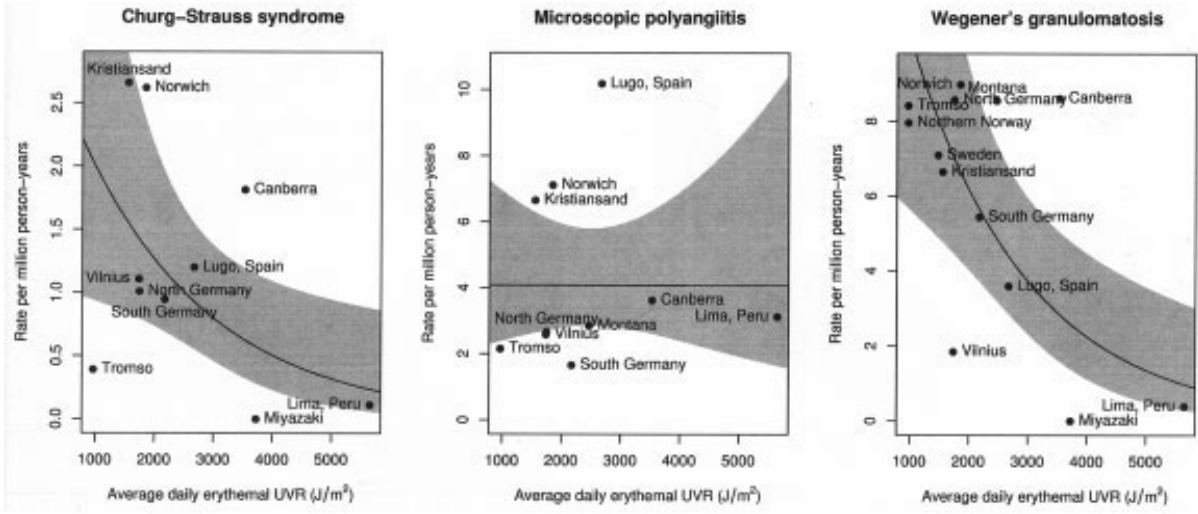

Figure 1. Variation in the crude incidence rate of the antineutrophil cytoplasmic antibodyassociated vasculitides with change in ambient erythemal ultraviolet radiation (UVR). The shaded area shows the $95 \%$ confidence limits. $\mathrm{J}=$ joules. 
[clear] IRR 0.39, 95\% CI 0.15-0.93; $P=0.03$ and winter UV $_{\text {vitD }}$ [cloud] IRR 0.19, 95\% CI 0.07-0.47; $P<0.001$ ).

In our second sensitivity analysis, we recalculated case numbers where, for example, only adult cases were included, using the proportion of childhood cases compared with adult cases where the entire population was the source. Because the AAVs are rare in childhood, this had little effect on the total case numbers. For example, in the study from Lithuania (33), the number of cases with WG increased from 10 to 10.18, increasing the incidence from 1.84 per million to 1.88 per million. Repeating the analyses with the adjusted values did not change the results above.

\section{DISCUSSION}

These results confirm a preliminary observation that WG is latitude related $(7,9)$, and quantify the magnitude of the gradient. We found a strong inverse association between measures of erythemal and vitamin D effective ambient UV radiation level and WG incidence, with a decrease in incidence of $38 \%$ (95\% CI 6-56\%) for every 1,000 joules $/ \mathrm{m}^{2}$ increase of $\mathrm{UV}_{\text {ery }}$ (clear). There was a similar, but with a lower magnitude, association for CSS, with a decrease in incidence of $23 \%$ (95\% CI $4-38 \%$ ) per 1,000 joules $/ \mathrm{m}^{2}$ increase in winter $\mathrm{UV}_{\mathrm{vitD}}$ (cloud). In contrast, MPA incidence did not appear to be associated with latitude or ambient UV radiation when all data points were considered, although point estimates were consistently greater than 1, with some strengthening of effect with exclusion of the Lima, Peru data. Absence of a latitudinal gradient in MPA is at odds with previously published work (9). This may reflect our exclusion of the Kuwait data (30) because the precise population from which the subjects were derived is not clear, and the incidence estimates are potentially overestimated. As previously noted, 1,000 joules $/ \mathrm{m}^{2}$ of $\mathrm{UV}_{\text {ery }}$ (clear) is approximately the difference in this measure between Vilnius, Lithuania $\left(1,733.11\right.$ joules $\left./ \mathrm{m}^{2}\right)$ and Lugo, Spain $\left(2,665.61\right.$ joules $\left./ \mathrm{m}^{2}\right)$ during their respective study periods.

There is some uncertainty in the UV radiation estimates related to the evaluation of cloud effects. However, our results were consistent whether clear sky or cloud inclusive, erythemal, or vitamin D effective UV radiation estimates were used. The effects appeared to be stronger only for winter measures of ambient UV radiation. To put our findings into some perspective, our results indicate that the incidence of WG increases by $3.4 \%$ per higher degree of latitude and CSS by 3.5\% per higher degree of latitude. The single comparable meta-analytic study of multiple sclerosis (46) found a nonsignificant latitudinal increase in age-adjusted incidence. From the data provided in their Figure 2, we estimate that this is of the order of a $\sim 4 \%$ increase in multiple sclerosis incidence per higher degree of latitude.

Ambient UV radiation was used as a proxy for populationlevel exposure to UV radiation and vitamin D status. However, at the population level, UV radiation exposure is affected by cultural and religious beliefs, e.g., clothing requirements or preference of pale or tanned skin, whereas within this context, individual-level sun exposure is highly behavior dependent (47). Vitamin D status depends not only on UV radiation exposure of the skin $(48,49)$, but on skin pigmentation (50), diet (51), and genetic factors (52). Furthermore, at higher latitudes, increased dietary vitamin D intake (53) may uncouple a direct association between UV radiation exposure and vitamin D status. We recognize the limitations of the ecological approach, but are not aware of any studies for which individual UV dosimetry data or blood vitamin D levels are yet available for the AAVs. Therefore, we could not unravel these components in this ecological analysis. The findings should be interpreted to reflect not only latitude-related ambient UV radiation levels, but also variation in these other factors, i.e., diet, skin pigmentation, and sun exposure behavior.

We chose to study the association between 2 latituderelated factors, ambient erythemal and vitamin $\mathrm{D}$ effective UV radiation levels. Other environmental factors such as infection and nutrition may also vary by latitude, as may genetic predisposition to these diseases. For example, HLA status, a strong influence on antigen-induced immune responses, varies by race (54). However, our analyses consistently show a much stronger effect size for measures of ambient UV radiation level compared with latitude, although we cannot rule out a role for regional factors that are strongly linked to ambient UV radiation level.

UV radiation exposure of the skin leads to both direct and indirect (via vitamin D) immunosuppression (reviewed by Ponsonby et al in 2005 [22]). Imputed vitamin D levels would give results parallel to our conclusions here in regard to UV radiation, but there are insufficient data about population- or subject-specific vitamin D levels to allow anything other than speculation. Nevertheless, there are plausible immune mechanisms involving vitamin $D_{3}$ inhibition of Th1 and Th17 cell proliferation and cytokine production, tilting the immune system toward Th2 cells (20) and enhancing the suppressive activity of the CD24+CD25+ so-called Treg cells $(55,56)$. WG is considered a Th1 and/or a Th17 cell-mediated autoimmune disease (57). A role for vitamin D (largely induced by UV radiation) in specifically suppressing Th1/Th17 cells and up-regulating Treg cells provides a biologically plausible explanation for the findings reported here.

The pathogenesis of CSS has not been dissected as effectively as WG. The occurrence of eosinophilia and elevated IgE levels is very suggestive of a Th2 cell response, which is not consistent with the above hypothesis with regard to WG. However, like WG, CSS is characterized by granuloma formation and we postulate that this aspect of the condition is likely to be Th1 cell driven (16).

Most evidence suggests that although Th1/Th17 cells may play a role in MPA, this condition is far more dependent on Th2 cells or antibody-related mechanisms than Th1 cells (1). In MPA, there is substantially stronger evidence for a pathogenetic role of the autoantibody antimyeloperoxidase than there is for anti-proteinase 3 in WG and no occurrence of granulomas $(16,58)$. Consequently, the lack of a latitude or UV radiation effect mediated through vitamin $\mathrm{D}$ is not unexpected in this particular AAV. 
Two major classification systems are used for vasculitis: the ACR and CHCC criteria. Either both of the systems or only the CHCC were used by most of the studies included in these analyses; 4 studies used only the ACR criteria $(33,38,59,60)$. Although MPA is only clearly defined in the CHCC criteria, the incidence of WG in those studies that used only the ACR criteria are consistent with that at other similar $(59,60)$ or lower $(33)$ latitude locations. Indeed, for the latter, the incidence of both WG and MPA is considerably lower than other similar latitude sites. The most likely misclassification when not using the CHCC criteria would be to include cases in the WG group that would now appropriately be designated MPA. This in effect would dilute the WG group at some of the sites and would weaken the association of WG and latitude and ambient UV radiation that we have demonstrated. Indeed, for a combined WG and MPA group, the associations are weaker than for WG alone and no longer statistically significant, although in the same direction. Therefore, for the combined data, the negative binomial regression with latitude demonstrates an increased incidence by $0.78 \%$ per higher degree of latitude (IRR 1.01, 95\% CI 0.99-1.11) and the correlation with $\mathrm{UV}_{\text {ery }}$ (clear) and winter $\mathrm{UV}_{\text {vitD }}$ (cloud) ( $\mathrm{r}=-0.43, P=0.22$ and $\mathrm{r}=-0.56, P=0.10$, respectively).

To our knowledge, this study is the first to quantify the magnitude of the latitudinal variation in the incidence of these AAVs and to examine the association with levels of both average and winter regional ambient UV radiation. Although there is modest latitudinal variation in average daily ambient UV radiation levels (across the entire year), this variation is increased for winter ambient UV radiation and may explain the stronger associations we observed between WG incidence and winter ambient UV radiation. In addition, we have standardized the data for age to ensure that the observed variation is not confounded by variations in the age structure of populations.

However, in this work, we have not controlled for possible ethnic and genetic differences in the underlying populations. Conceivably, the very low reported incidence of WG in Kuwait (30), Japan (35), and Lima, Peru (61) could be caused by differences in genetic susceptibility of the underlying populations. Nevertheless, a prevalence survey within a relatively genetically homogeneous population, the New Zealand European population, provides supportive evidence for a latitudinal gradient in WG that is not confounded by variation in ethnicity (8). Clearly, this current study provides no clues to explain the dearth of AAVs in individuals of African American descent $(32,62)$; however, a similar pattern is seen in multiple sclerosis, another autoimmune disease with a striking latitudinal pattern of occurrence (63). One focus of future work could be to examine the role of ethnicity in the development of the AAVs.

Here we have used the available literature reporting the population-based incidence of AAVs to explore possible etiologic associations with measures of ambient UV radiation. We observed a strong inverse association between the incidence of WG and measures of ambient UV radiation, with a lesser association for CSS and no association for MPA. The association with UV radiation (by either direct or indirect pathways mediated by enhancement of vitamin D synthesis) is biologically plausible through effects on Th1 and Th17 cell immune function and Treg cells. We regard these findings as important and, as has occurred in multiple sclerosis and type 1 diabetes mellitus, they should lead to the generation of etiologic hypotheses that can be more directly explored in individual-level epidemiologic studies.

\section{ACKNOWLEDGMENTS}

We gratefully acknowledge access to Total Ozone Mapping Spectrometer and Ozone Mapping Instrument ozone and UV radiation data from the NASA Goddard Space Flight Center and to Dobson and Brewer ozone data from the World Ozone and Ultraviolet Radiation Data Centre.

\section{AUTHOR CONTRIBUTIONS}

All authors were involved in drafting the article or revising it critically for important intellectual content, and all authors approved the final version to be published. Dr. Gatenby had full access to all of the data in the study and takes responsibility for the integrity of the data and the accuracy of the data analysis.

Study conception and design. Gatenby, Lucas.

Acquisition of data. Gatenby, Lucas, Engelsen.

Analysis and interpretation of data. Gatenby, Lucas, Engelsen, Ponsonby, Clements.

\section{REFERENCES}

1. Kallenberg CG. Antineutrophil cytoplasmic autoantibodyassociated small-vessel vasculitis. Curr Opin Rheumatol 2007;19:17-24.

2. Jennette JC, Falk RJ. Nosology of primary vasculitis. Curr Opin Rheumatol 2007;19:10-6.

3. Hewins P, Tervaert JW, Savage CO, Kallenberg CG. Is Wegener's granulomatosis an autoimmune disease? Curr Opin Rheumatol 2000;12:3-10.

4. Clayton AR, Savage CO. What you should know about PR3ANCA: evidence for the role of T cells in the pathogenesis of systemic vasculitis. Arthritis Res 2000;2:260-2.

5. Bonaci-Nikolic B, Nikolic MM, Andrejevic S, Zoric S, Bukilica M. Antineutrophil cytoplasmic antibody (ANCA)associated autoimmune diseases induced by antithyroid drugs: comparison with idiopathic ANCA vasculitides. Arthritis Res Ther 2005;7:R1072-81.

6. Short AK, Lockwood CM. Antigen specificity in hydralazine associated ANCA positive systemic vasculitis. QJM 1995;88: 775-83.

7. Mahr AD, Neogi T, Merkel PA. Epidemiology of Wegener's granulomatosis: lessons from descriptive studies and analyses of genetic and environmental risk determinants. Clin Exp Rheumatol 2006;24 Suppl 41:S82-91.

8. O’Donnell JL, Stevanovic VR, Frampton C, Stamp LK, Chapman PT. Wegener's granulomatosis in New Zealand: evidence for a latitude-dependent incidence gradient. Intern Med J 2007;37:242-6.

9. De Lind van Wijngaarden RA, van Rijn L, Hagen EC, Watts RA, Gregorini G, Tervaert JW, et al. Hypotheses on the etiology of antineutrophil cytoplasmic autoantibody associated vasculitis: the cause is hidden, but the result is known. Clin J Am Soc Nephrol 2008;3:237-52.

10. McLeod JG, Hammond SR, Hallpike JF. Epidemiology of multiple sclerosis in Australia: with NSW and SA survey results. Med J Aust 1994;160:117-22.

11. Staples JA, Ponsonby AL, Lim LL, McMichael AJ. Ecologic analysis of some immune-related disorders, including type 1 diabetes, in Australia: latitude, regional ultraviolet radiation, 
and disease prevalence. Environ Health Perspect 2003;111: $518-23$.

12. Armitage EL, Aldhous MC, Anderson N, Drummond HE, Riemersma RA, Ghosh S, et al. Incidence of juvenile-onset Crohn's disease in Scotland: association with northern latitude and affluence. Gastroenterology 2004;127:1051-7.

13. Compston A. 'The marvellous harmony of the nervous parts': the origins of multiple sclerosis. Clin Med 2004;4:346-54.

14. Wucherpfennig KW, Eisenbarth GS. Type 1 diabetes. Nat Immunol 2001;2:767-8.

15. Ludviksson BR, Sneller MC, Chua KS, Talar-Williams C, Langford CA, Ehrhardt RO, et al. Active Wegener's granulomatosis is associated with HLA-DR + CD4 + T cells exhibiting an unbalanced Th1-type T cell cytokine pattern: reversal with IL-10. J Immunol 1998;160:3602-9.

16. Lamprecht P. Off balance: T-cells in antineutrophil cytoplasmic antibody (ANCA)-associated vasculitides. Clin Exp Immunol 2005;141:201-10.

17. Abdulahad WH, van der Geld YM, Stegeman CA, Kallenberg CG. Persistent expansion of CD4+ effector memory T cells in Wegener's granulomatosis. Kidney Int 2006;70:938-47.

18. Csernok E, Ai M, Gross WL, Wicklein D, Petersen A, Lindner $\mathrm{B}$, et al. Wegener autoantigen induces maturation of dendritic cells and licenses them for Th1 priming via the proteaseactivated receptor-2 pathway. Blood 2006;107:4440-8.

19. Tesmer LA, Lundy SK, Sarkar S, Fox DA. Th17 cells in human disease. Immunol Rev 2008;223:87-113.

20. Arnson Y, Amital H, Shoenfeld Y. Vitamin D and autoimmunity: new aetiological and therapeutic considerations. Ann Rheum Dis 2007;66:1137-42.

21. Muller K, Bendtzen K. 1,25-Dihydroxyvitamin D3 as a natural regulator of human immune functions. J Investig Dermatol Symp Proc 1996;1:68-71.

22. Ponsonby AL, Lucas RM, van der Mei IA. UVR, Vitamin D and three autoimmune diseases: multiple sclerosis, type 1 diabetes, rheumatoid arthritis. Photochem Photobiol 2005;81: 1267-75.

23. Daniel C, Sartory NA, Zahn N, Radeke HH, Stein JM. Immune modulatory treatment of trinitrobenzene sulfonic acid colitis with calcitriol is associated with a change of a T helper (Th) 1/Th17 to a Th2 and regulatory T cell profile. J Pharmacol Exp Ther 2008;324:23-33.

24. Webb AR, Holick MF. The role of sunlight in the cutaneous production of vitamin D3. Annu Rev Nutr 1988;8:375-99.

25. Jablonski NG, Chaplin G. The evolution of human skin coloration. J Hum Evol 2000;39:57-106.

26. Lucas RM, Ponsonby AL. Considering the potential benefits as well as adverse effects of sun exposure: can all the potential benefits be provided by oral vitamin D supplementation? Prog Biophys Mol Biol 2006;92:140-9.

27. Reinhold-Keller E, Herlyn K, Wagner-Bastmeyer R, Gutfleisch $\mathrm{J}$, Peter $\mathrm{HH}$, Raspe HH, et al. No difference in the incidences of vasculitides between north and south Germany: first results of the German Vasculitis Register. Rheumatology (Oxford) 2002;41:540-9.

28. Hunder GG, Arend WP, Bloch DA, Calabrese LH, Fauci AS, Fries JF, et al. The American College of Rheumatology 1990 criteria for the classification of vasculitis. Arthritis Rheum 1990;33:1065-144.

29. Jennette JC, Falk RJ, Andrassy K, Bacon PA, Churg J, Gross WL, et al. Nomenclature of systemic vasculitides: proposal of an international consensus conference. Arthritis Rheum 1994; 37:187-92.

30. El-Reshaid K, Kapoor MM, el-Reshaid W, Madda JP, Varro J. The spectrum of renal disease associated with microscopic polyangiitis and classic polyarteritis nodosa in Kuwait. Nephrol Dial Transplant 1997;12:1874-82.

31. Tidman M, Olander R, Svalander C, Danielsson D. Patients hospitalized because of small vessel vasculitides with renal involvement in the period 1975-95: organ involvement, antineutrophil cytoplasmic antibodies patterns, seasonal attack rates and fluctuation of annual frequencies. J Intern Med 1998;244:133-41.

32. Falk R, Hogan S, Carey T, Jennette J, for the Glomerular
Disease Collaborative Network. Clinical course of anti-neutrophil cytoplasmic autoantibody-associated glomerulonephritis and systemic vasculitis. Ann Intern Med 1990;113:656-63.

33. Dadoniene J, Kirdaite G, Mackiewicz Z, Rimkevicius A, Haugeberg G. Incidence of primary systemic vasculitides in Vilnius: a university hospital population based study [letter]. Ann Rheum Dis 2005;64:335-6.

34. Zeft A, Schlesinger M, Weiss N, Emery H. Case control study of ANCA associated vasculitis in western Montana [abstract]. Arthritis Rheum 2005;52 Suppl:S648.

35. Fujimoto S, Uezono S, Hisanaga S, Fukudome K, Kobayashi S, Suzuki K, et al. Incidence of ANCA-associated primary renal vasculitis in the Miyazaki Prefecture: the first populationbased, retrospective, epidemiologic survey in Japan. Clin J Am Soc Nephrol 2006;1:1016-22.

36. Watts RA, Scott DG, Jayne DR, Ito-Ihara T, Muso E, Fujimoto $S$, et al. Renal vasculitis in Japan and the UK: are there differences in epidemiology and clinical phenotype? Nephrol Dial Transplant 2008;23:3928-31.

37. Watts RA, Lane SE, Bentham G, Scott DG. Epidemiology of systemic vasculitis: a ten-year study in the United Kingdom. Arthritis Rheum 2000;43:414-9.

38. Koldingsnes W, Nossent H. Epidemiology of Wegener's granulomatosis in northern Norway. Arthritis Rheum 2000;43: 2481-7.

39. Gonzalez-Gay MA, Garcia-Porrua C, Guerrero J, RodriguezLedo P, Llorca J. The epidemiology of the primary systemic vasculitides in northwest Spain: implications of the Chapel Hill Consensus Conference definitions. Arthritis Rheum 2003; 49:388-93.

40. McKinlay AF, Diffey BL. A reference action spectrum for ultra-violet induced erythema in human skin. CIE J 1987;6: $17-22$.

41. International Commission on Illumination (CIE). Action spectrum for the production of previtamin D3 in human skin. 2006. URL: http://www.cie.co.at/publ/abst/174-06.html.

42. Frederick JE, Slusser JR, Bigelow DS. Annual and interannual behavior of solar ultraviolet irradiance revealed by broadband measurements. Photochem Photobiol 2000;72:488-96.

43. Lawless J. Negative binomial and mixed Poisson regression. Can J Stat 1987;15:209-25.

44. Cook RD. Influential observations in linear regression. J Am Stat Assoc 1979;74:169-74.

45. Belsley D, Kuh E, Welsch R. Regression diagnostics: identifying influential data and sources of colinearity. New York: Wiley Interscience; 2004.

46. Zivadinov R, Iona L, Monti-Bragadin L, Bosco A, Jurjevic A, Taus C, et al. The use of standardized incidence and prevalence rates in epidemiological studies on multiple sclerosis: a meta-analysis study. Neuroepidemiology 2003;22:65-74.

47. Gies P, Roy CR, McLennan A, Tomlinson DW. Trends in ultraviolet radiation: trends in sun protection seminar. Victoria (Australia): Anti Cancer Council of Victoria; 1999.

48. Matsuoka LY, Wortsman J, Hanifan N, Holick MF. Chronic sunscreen use decreases circulating concentrations of 25hydroxyvitamin D: a preliminary study. Arch Dermatol 1988; 124:1802-4.

49. Holick MF. Environmental factors that influence the cutaneous production of vitamin D. Am J Clin Nutr 1995;61 Suppl: 638S-45S.

50. Matsuoka LY, Wortsman J, Haddad JG, Hollis BW. Skin types and epidermal photosynthesis of vitamin D3. J Am Acad Dermatol 1990;23:525-6.

51. Hollis BW. Circulating 25-hydroxyvitamin D levels indicative of vitamin D sufficiency: implications for establishing a new effective dietary intake recommendation for vitamin D. J Nutr 2005;135:317-22.

52. Sinotte M, Diorio C, Berube S, Pollak M, Brisson J. Genetic polymorphisms of the vitamin $\mathrm{D}$ binding protein and plasma concentrations of 25-hydroxyvitamin $\mathrm{D}$ in premenopausal women. Am J Clin Nutr 2009;89:634-40.

53. Scharla S. Epidemiology of vitamin D deficiency/insufficiency in different European countries. J Menopause 2000;2 Suppl:29-33. 
54. Ghodke Y, Joshi K, Chopra A, Patwardhan B. HLA and disease. Eur J Epidemiol 2005;20:475-88.

55. Gorman S, Kuritzky LA, Judge MA, Dixon KM, McGlade JP, Mason RS, et al. Topically applied 1,25-dihydroxyvitamin D3 enhances the suppressive activity of CD $4+\mathrm{CD} 25+$ cells in the draining lymph nodes. J Immunol 2007;179:6273-83.

56. Penna G, Amuchastegui S, Giarratana N, Daniel KC, Vulcano $\mathrm{M}$, Sozzani S, et al. 1,25-Dihydroxyvitamin D3 selectively modulates tolerogenic properties in myeloid but not plasmacytoid dendritic cells. J Immunol 2007;178:145-53.

57. Kallenberg CG. Pathogenesis of PR3-ANCA associated vasculitis. J Autoimmun 2008;30:29-36.

58. Jennette JC, Falk RJ. New insight into the pathogenesis of vasculitis associated with antineutrophil cytoplasmic autoantibodies. Curr Opin Rheumatol 2008;20:55-60.

59. Knight A, Ekbom A, Brandt L, Askling J. Increasing incidence of Wegener's granulomatosis in Sweden, 1975-2001. J Rheumatol 2006;33:2060-3.

60. Haugeberg G, Bie R, Bendvold A, Larsen AS, Johnsen V. Primary vasculitis in a Norwegian community hospital: a retrospective study. Clin Rheumatol 1998;17:364-8.

61. Sanchez-Torres A, Acevedo-Vasquez E, Sanchez-Schwartz C, Pastor-Asurza C, Perich-Campos R, Alfaro-Lozano J, et al.
Incidences of the primary systemic vasculitides in a Peruvian population [abstract]. J Clin Rheumatol 2006;4 Suppl:S75.

62. Cotch MF, Hoffman GS, Yerg DE, Kaufman GI, Targonski P, Kaslow RA. The epidemiology of Wegener's granulomatosis: estimates of the five-year period prevalence, annual mortality, and geographic disease distribution from population-based data sources. Arthritis Rheum 1996;39:87-92.

63. Kurtzke JF, Beebe GW, Norman JE Jr. Epidemiology of multiple sclerosis in U.S. veterans. 1. Race, sex, and geographic distribution. Neurology 1979;29:1228-35.

64. Ormerod A, Cook M. Epidemiology of primary systemic vasculitis in south-eastern Australia. Intern Med J 2008;38:81623.

65. Reinhold-Keller E, Herlyn K, Wagner-Bastmeyer R, Gross WL. Stable incidence of primary systemic vasculitides over five years: results from the German Vasculitis Register. Arthritis Rheum 2005;53:93-9.

66. Watts RA, Gonzalez-Gay MA, Lane SE, Garcia-Porrua C, Bentham G, Scott DG. Geoepidemiology of systemic vasculitis: comparison of the incidence in two regions of Europe. Ann Rheum Dis 2001;60:170-2.

67. Watts RA, Lane SE, Scott DG, Koldingsnes W, Nossent H, Gonzalez-Gay MA, et al. Epidemiology of vasculitis in Europe [letter]. Ann Rheum Dis 2001;60:1156-7. 